\title{
Effect of an Exercises Programme on Reducing Musculoskeletal Complications for Stroke Immobilized Patients
}

\author{
Marwa Ali. Elmasry, Zienab Abd El-Lateef. Mohammad, Ghaydaa Ahmed. Shehat \& Hala Mohammed. \\ Ghanem \\ Assistant lecturer of Adult Nursing- Faculty of Nursing- Assiut University, Egypt \\ Professor and Head of Adult Nursing Department- Faculty of Medicine, Assiut University, Egypt \\ Professor of Neurological Department - Faculty of Medicine- Assiut University, Egypt \\ Assistant Professor of Adult nursing- Faculty of Nursing- Assiut University, Egypt
}

\begin{abstract}
Stroke is a leading cause of disability. Aim: the first assess patient's knowledge and practice regarding musculoskeletal complications resulting from immobility. The second evaluate the effect of applying for an exercise programme on stroke immobilized patients' knowledge and practice. Patient methods: 60 patients conducted at neurological departments at Assiut University Hospital. . Tools: Data collected by using three tools; Tool I: Patient's health needs assessment sheet: part 1; A- included Sociodemographic patient characteristics, B- socio-demographic scale, according to Fahmy and Al-sherbeny (1983), part 2; assessment of the past and present health history, part 3; patient's Assessment for the musculoskeletal complications, Part 4: Assessment of patient's knowledge and practice regarding musculoskeletal complications resulting from immobility and importance of these exercises, Tool IIMusculoskeletal assessment sheet: Part 1; by Ashworth scale ,1964, Part 2; Scandinavian stroke scale,1991. Results: The incidences of musculoskeletal complications in the study sample were lesser than the control group and having higher mean score knowledge regarding stroke. Conclusions: providing a successful physical exercise programme for stroke patients was much more effective on the outcome of patients than those patients in the control group who received routine hospital care. Also, the mean score level of knowledge of the study group patients in the time of follow-up was higher than the mean score level of knowledge of control group patients who didn't receive the exercise programme. Recommendations: the exercise programme should be applying early as possible as from at the time of admission to the hospital.
\end{abstract}

Keywords: Immobilized Stroke Patients, Exercise Programme, Musculoskeletal Complications.

\section{Introduction}

Stroke defined according to National Institute of Neurologic Disorder and Stroke (NINDS) and the World Health Organization (WHO) as loss of the brain function related to inadequate cerebrovascular blood flow for a duration of at least 24 hours (Carison, 2009).

Stroke is the third leading cause of death and the leading cause of adult disability in the United States. Approximately 780,000 Americans experience strokes each year, resulting in the death of approximately 136,000 people annually. An additional 200,000 to 500,000 individuals experience a transient ischemic attacks (TIA). The economic effect of stroke is estimated to be more than $\$ 60$ billion each year. Approximately 5,500,000 Americans are stroke survivors. Stroke is considered one of the most preventable of catastrophic events in the United States. (Lina et al., 2012).

Stroke is the second most common cause of death and among the top five causes of morbidity in many developed and developing countries the burden of stroke in developing countries has grown to epidemic proportions. Two-thirds of global stroke occurs in low- and middle-income countries. We have found that little information is obtainable concerning the availability of thrombolysis therapy in developing countries (Masoud et al., 2012). The incidence of stroke was highly significant in males compared to females. Acute cerebrovascular stroke was highly associated with hypertension, diabetes mellitus, smoking and atrial fibrillation, the incidence of cerebral infarction was highly significant than intracranial hemorrhage. There was an increase in the incidence of cerebral infarction with the increase in age in a significant way. Also, there was a decrease in the incidence of intracranial hemorrhage with the increase in age in a significant way (Ayman et al., 2011).

There is considerable loss of strength when a muscle is put at rest. This occurs even with relatively short periods of immobility. With each day of bed rest, there is as much as $3 \%$ loss of muscle strength or up to $20 \%$ loss of residual strength per week of immobilization. Lower extremity muscles lose their strength about twice as fast as upper extremity muscles (Mullar.,1970). 
Disuse of the muscles leads to atrophy and a loss of muscle strength at a rate of around $12 \%$ a week. After 3-5 weeks of bedrest, almost half the normal strength of a muscle is lost (Jiricka, 2008). This means that there can be as much as a $50 \%$ loss of muscle strength in as little as 3 weeks of bed rest. Unfortunately, subsequent recovery of strength proceeds at a much slower pace. Once immobilization has ceased, the most rapid rate of strength recovery is approximately $10 \%$ per week. Thus, it is far more efficient to prevent loss of strength secondary to immobilization. Prevention will have important ramifications on the speed at which injured soldiers can be returned to duty (Mullar,1970).

The benefits of physical activity, including recommendations for prescribing exercise for stroke survivors across all stages of recovery. Importantly, despite the physical limitations, many of these stroke survivors have the ability to undertake higher levels of physical activity but choose not to do so. The writing group indicates that the likely reasons for limited exercise participation by stroke patients include a lack of awareness that exercise is feasible or desirable, access to resources to support exercise, and structured exercise sessions whereby exercises could be demonstrated by a rehabilitation specialist or exercise leader (Banks et al., 2012).

\section{Aims of study}

1. To assess patient's knowledge and practice regarding musculoskeletal complications resulting from immobility and importance of these exercises.

2. To evaluate the effect of applying for an exercise programme on stroke immobilized patients' knowledge and practice regarding these complications.

\section{Hypotheses}

To fulfill the aims of the study the following research hypotheses were formulated:

- The mean knowledge scores of the study group who will be received the exercise programme will be higher than mean knowledge scores of the control group.

- The mean practice scores of the study group who will be applying exercise programme will be higher than mean practice scores of the control group.

- A positive relationship will exist between knowledge and practice scores obtained by patients receiving the exercises programme.

- The incidence of musculoskeletal complications after implementation of the exercises programme in the study group will be lesser than those in the control group.

\section{Significance of the study}

The stroke patients are exposed to numerously attended risks and musculoskeletal complications due to immobility. So, they should have knowledge and practice enable them to deal with these complications. The stroke immobilized patients are needed to exercises programme to reduce musculoskeletal complications that resulting from immobility and to restore range of motion.

\section{Patients \& Methods}

Study design: Quasi-experimental research design was utilized to meet the aim of the study.

\section{Study settings}

The study was conducted at Neurological departments and Neurological outpatient clinic of Assiut University Hospital.

\section{Subjects}

The study include of a convenience sample of 60 adult immobile patients' stroke from a time of admission in the neurological departments and those patients were followed up before the discharge from a hospital and after 2 month. This sample was divided into two equal groups; the study and the control groups (30 patients for each). The study group (30 patients who received exercises programme which applied by the researcher and the effect of this programme on the patients evaluated through a period of a follow-up). While the control group (30 patients who will receive routine care of a hospital). Selected according to the following criteria:

1. The age ranged between 18-65 years old.

2. Recent admission to hospital.

3. Any type of stroke (ischemic or hemorrhagic).

Tools

Three tools utilized for data collection to achieve the study purpose.

Tool I: Patient's health needs assessment sheet: This tool consisted of four parts:

Part (1): A- Sociodemographic patient characteristics: this sheet was used prior to implementation of the exercise programme to selected socio-demographic data for a stroke immobilized patients which consisted of Patient's name, age, gender, level of education, occupation, patient's diagnosis, admission date, discharge date and length of stay.

B- Sociodemographic scale, according to Fahmy and Al-sherbeny (1983); which consisted of father's education included 3 items, mother's education included 10 items, monthly income every month included 4 items, crowding index included 4 items and sanitation included 3 items. The total items equal 5 . 
Scoring system of the Sociodemographic scale, according to Fahmy and El-Sher Bini 1983:

- Total socioeconomic score $=23$ scores

- Scores <15 are considered of low socioeconomic standard

- Scores 15-<19 are considered of middle socioeconomic standard

- Scores 19+ are considered of high socioeconomic standard

Part (2): Patient's health assessment for stroke immobilized patient:

This sheet was used prior to implementation of the exercise programme to assess the past and present health history; which consisted of onset of stroke, the number of attack recurrence, causes of stroke affected paralytic side and types of stroke.

Part 3: patient's Assessment for the musculoskeletal complications.

It was used to assess expected complications that might develop among stroke immobilized patients admitted to the neurological department prior to implementation of the exercise programme, before discharge from a hospital and after 2 months.

- Muscles atrophy

- Joint pain.

- Muscle spasticity ( $\uparrow$ tone)

- Muscles flaccid ( $\downarrow$ tone)

- Limited ROM

- Stiff joints

- Painful hemiplegic shoulder

- Shoulder subluxation

- Knee flexion contracture

- Foot drop

- Toe curling

- Finger curling.

Part (4): Assessment of stroke immobilized patient's knowledge and practice regarding musculoskeletal complications resulting from immobility and importance of these exercises; It includes the following:

- Assessment of patient's knowledge regarding stroke, types, risk factor, a complication of the musculoskeletal system that resulting from immobility. This tool was used prior to implementation of the exercise programme, before discharge from a hospital and after 2 months, used to evaluate the stroke patients' knowledge. The total number of questions was 17 .

\section{Scoring system}

The total score of knowledge were (17). Using score system for knowledge, a correct response was scored (1) grade and zero for the incorrect (Unsatisfactory = score $<60 \%$, satisfactory score $\geq 60 \%$ ).

- Assessment of patient's practices regarding aim and types of the exercises. Scoring system translated in results into adequate and inadequately practice according to answer the total scores were 10.

Scoring system: Total score of practice were (10). Using score system for practice, a correct response was scored (1) grade and zero for the incorrect (inadequate $=$ score $<50 \%$, adequate score $\geq 50 \%$ ).

\section{Tool II- Exercises programme:}

This tool was developed based around the content of the best practice statement for exercises it included theoretical part (brief anatomy, definition, types, risk factors, signs and symptoms of stroke, method of prevention musculoskeletal system overview and complications of immobility) and practical part( good positioning and passive range of motion exercise) for completion and application by the researcher. (National stroke association, 2010).

Tool III- Musculoskeletal assessment sheet:

Part 1: according to Ashworth scale, 1964: Assessment of the degree of muscles strength. The scoring system, no increase in muscle tone have a score (0) while a score of (4) is given when movement limb with full resistance. This tool was used prior to implementation of the exercise programme, before discharge from a hospital and after 2 months, used to measure muscles strength.

Part 2: according to Scandinavian stroke scale, Lindenstrom, 1991. This tool was used prior to implementation of the exercise programme, before discharge from a hospital and after 2 months, used to measure muscles strength, used to assessment the power of limb movement. This consisted of:

- Consciousness

- Eye movement

- Arm, motor power

- Hand, motor power

- Leg, motor power

- Orientation

- Speech

- Facial palsy

- Gait

Scoring system: of the present result low, moderate and high grade of the total maximum score. Those who obtained $(\leq 50 \%)$ were graded as a low score. While those; who obtained more than $(50-70 \%)$ were graded as moderate score and the patient who obtained ( $\geq 75$ ) were graded as a high score. There are no scoring systems for the present scale and, therefore, constructed a scale adjusted for use by nonneurologists", but it is better when the scores are greater.

\section{Methods}

\section{The study was conducted through}

- Data were collected at Neurological departments and Neurological outpatient clinic of Assiut 
University Hospital during the period from August 2014 to August 2015.

- An official permission was obtained from the head of Neurological department at Assiut University Hospital.

- The study tools and exercises programme were formulated after a review of the literature.

- The content validity was done by 5 expertises in the medical surgical nursing field and neurology field.

- Patient's agreement for voluntary participation was obtained after the purpose and nature of the study were explained.

- Data were assured confidentiality and anonymity and were collected using the pre-mentioned study tools.

- A pilot study was conducted on $10 \%$ (6) of patients to examine the feasibility of the study and clarity of the tools.

- The study was carried during the evening shift for all available patients.

- After the acute phase of the disease over three days from entering the stroke patient to the neurological department; the researcher meet with each patient individually.

- After assessment of the patient's needs by ( a tool I and tool II) this sheet were used prior to implementation of the exercise programme.

- The exercises programme was started as early as possible after admission with three days to prevent musculoskeletal complications for stroke patients.

- The exercise programme would be provided to the study group on short sessions of 30 minutes once a day from two to three times a week (using tool II).

- Each patient in the study group obtained a copy of the programme.

- Before the patient's discharge from the hospital and after two months, the researcher meets the patient for follow-up in the neurological outpatient clinic (using the tool I part 3 and 4) and (tool III) to evaluate the patients' muscles strength and the power of limb movement.

- The patient and patients' relatives educated about how to apply for exercise programme before discharge from the hospital.

\section{Protection of human rights}

Each patient was informed with the purpose of the study. The investigator emphasized that the participation is voluntary and confidentially and anonymity of subjects assured through coding of all data, and protection of the patient from hazard. Verbal consent was obtained from each patient prior to his/her contribution in the present study. Confidentiality of any obtained information was secured.

\section{Statistical design}

Data collected and analysis by computer program SPSS" ver. 17" Chicago .USA Data expressed as mean, Standard Deviation, number, and Percentage. Using $\mathrm{T}$ - test to determine significant for the numeric variable. Using Chi-square to determine significant for the non-parametric variable.

- $\mathrm{P}>0.05$ non-significant

- $\mathrm{P}<0.05$ significant

- $\mathrm{P}<0.005$ moderate significant

- $\mathrm{P}<0.001$ highly significant

Limitations of the study

- Patients who do not comply with the scheduled follow-up visits were excluded from the study.

- Some patient's physical status may interfere with the ability to apply exercise programme were excluded from the study as a patient suffering from deep venous thrombosis.

- The patient routine hospital physiotherapy begins at the time of discharge from the hospital.

There is few source about the effect of immobility on musculoskeletal complications for stroke patients. 


\section{Results}

Table (1): Socio-demographic characteristic and Fahmy and Al-sherbeeny scale of the studies group (control group and study group $)($ no=60).

\begin{tabular}{|c|c|c|c|c|c|}
\hline \multirow{2}{*}{ Items } & \multicolumn{2}{|c|}{ Study } & \multicolumn{2}{|c|}{ Control } & \multirow[t]{2}{*}{ P. value } \\
\hline & No. & $\%$ & No. & $\%$ & \\
\hline \multicolumn{6}{|l|}{ Age } \\
\hline $18-30$ & 1 & 3.3 & 1 & 3.3 & \multirow{3}{*}{$0.945^{\mathrm{ns}}$} \\
\hline $31-45$ & 6 & 20.0 & 5 & 16.7 & \\
\hline $46+$ & 23 & 76.7 & 24 & 80.0 & \\
\hline Range & \multicolumn{2}{|c|}{$29-75$} & \multicolumn{2}{|c|}{$27-65$} & \multirow{2}{*}{$0.528^{\mathrm{ns}}$} \\
\hline Mean+SD & \multicolumn{2}{|c|}{$55.5 \pm 11.5$} & \multicolumn{2}{|c|}{$53.7 \pm 9.9$} & \\
\hline \multicolumn{6}{|l|}{ Gender } \\
\hline Male & 16 & 53.3 & 17 & 56.7 & \multirow{2}{*}{$0.438^{\mathrm{ns}}$} \\
\hline Female & 14 & 46.7 & 13 & 43.3 & \\
\hline \multicolumn{6}{|l|}{ Level of Education } \\
\hline High education & 5 & 16.7 & 4 & 13.3 & \multirow{4}{*}{$0.624^{\mathrm{ns}}$} \\
\hline Secondary education & 2 & 6.7 & 5 & 16.7 & \\
\hline Read and write & 5 & 16.7 & 6 & 20.0 & \\
\hline Illiterate & 18 & 60.0 & 15 & 50.0 & \\
\hline \multicolumn{6}{|l|}{ Occupation } \\
\hline House wife & 15 & 50.0 & 14 & 46.7 & \multirow{4}{*}{$0.759^{\mathrm{ns}}$} \\
\hline Farmer & 10 & 33.3 & 10 & 33.3 & \\
\hline Employee & 3 & 10.0 & 2 & 6.7 & \\
\hline Not work & 2 & 6.7 & 4 & 13.3 & \\
\hline \multicolumn{6}{|l|}{ Patients Diagnosis } \\
\hline Cerberalhaemorrhage & 6 & 20.0 & 8 & 26.7 & \multirow{2}{*}{$0.542^{\mathrm{ns}}$} \\
\hline Cerberal Infarction & 24 & 80.0 & 22 & 73.3 & \\
\hline Length of Stay $(\mathrm{m} \pm \mathrm{sd})$ & \multicolumn{2}{|c|}{$13.9 \pm 5.6$} & \multicolumn{2}{|c|}{$17.5+6.4$} & $0.024 *$ \\
\hline \multicolumn{6}{|c|}{ fahmey and Al-sherbeeny social scale } \\
\hline Low & 25 & 83.4 & 24 & 80.0 & \multirow{3}{*}{$0.288^{\mathrm{ns}}$} \\
\hline Middle & 4 & 13.3 & 2 & 6.7 & \\
\hline High & 1 & 3.3 & 4 & 13.3 & \\
\hline
\end{tabular}


Table (2): Percentage distribution of the studied group (control group and study group) as regard health $\operatorname{assessment}($ no $=60)$.

\begin{tabular}{|c|c|c|c|c|c|c|}
\hline \multirow{2}{*}{ Variables } & \multicolumn{2}{|c|}{ Study } & \multicolumn{2}{|c|}{ Control } & \multicolumn{2}{|c|}{ Total } \\
\hline & No. & $\%$ & No. & $\%$ & No. & $\%$ \\
\hline Onset of stroke, $($ mean+SD $)$ & \multicolumn{2}{|c|}{$7.3 \pm 6.5$} & \multicolumn{2}{|c|}{$8.7 \pm 6.4$} & \multicolumn{2}{|c|}{$8.0 \pm 6.5$} \\
\hline \multicolumn{7}{|l|}{ Number of attack recurrence } \\
\hline First time & 20 & 66.7 & 25 & 83.3 & 45 & 75.0 \\
\hline Recurrent stroke & 10 & 33.3 & 5 & 16.7 & 15 & 25.0 \\
\hline \multicolumn{7}{|l|}{ Types of stroke } \\
\hline Ischemic stroke & 24 & 80.0 & 22 & 73.3 & 46 & 76.7 \\
\hline Hemorrhagic stroke & 6 & 20.0 & 8 & 26.7 & 14 & 23.3 \\
\hline \multicolumn{7}{|l|}{ Causes of stroke } \\
\hline Atherosclerosis & 1 & 3.3 & 1 & 3.3 & 2 & 3.3 \\
\hline Atrial fibrillation & 1 & 3.3 & 2 & 6.7 & 3 & 5.0 \\
\hline Diabetes mellitus & 1 & 3.3 & 0 & 0.0 & 1 & 1.7 \\
\hline Heart disease & 3 & 10.0 & 1 & 3.3 & 4 & 6.7 \\
\hline Hyperlipidemia & 1 & 3.3 & 0 & 0.0 & 1 & 1.7 \\
\hline Hypertension & 23 & 76.7 & 26 & 86.7 & 49 & 81.7 \\
\hline Unknown & 1 & 3.3 & 1 & 3.3 & 2 & 3.3 \\
\hline \multicolumn{7}{|l|}{ Affected paralytic side } \\
\hline Right & 13 & 43.0 & 12 & 40.0 & 24 & 83.3 \\
\hline Left & 17 & 56.7 & 18 & 60.0 & 35 & 58.3 \\
\hline \multicolumn{7}{|l|}{ Health history } \\
\hline Family history of stroke & 3 & 10.0 & 5 & 16.7 & 8 & 13.3 \\
\hline High blood pressure & 23 & 76.7 & 25 & 83.3 & 48 & 80.0 \\
\hline Heart disease & 7 & 23.3 & 8 & 26.7 & 15 & 25.0 \\
\hline Hyperlipidemia & 2 & 6.7 & 4 & 13.3 & 6 & 10.0 \\
\hline Smoking cigarettes & 2 & 6.7 & 6 & 20.0 & 8 & 13.3 \\
\hline Diabetic patient & 10 & 33.3 & 14 & 46.7 & 24 & 40.0 \\
\hline Obesity and overweight & 6 & 20.0 & 0 & 0.0 & 6 & 10.0 \\
\hline
\end{tabular}

Table (3): Comparison between study and control groups as regard pre-implementing, before discharge and after 2 months of assessment for the musculoskeletal complications for stroke patients $(\mathrm{no}=60)$.

\begin{tabular}{|c|c|c|c|c|c|c|c|c|c|c|c|c|c|c|c|}
\hline \multirow{3}{*}{ variables } & \multicolumn{4}{|c|}{ Pre-implementing } & \multirow{3}{*}{ P. value } & \multicolumn{4}{|c|}{ Before discharge } & \multirow{3}{*}{ P. value } & \multicolumn{4}{|c|}{ After 2 months } & \multirow{3}{*}{ P. value } \\
\hline & \multicolumn{2}{|c|}{ Study } & \multicolumn{2}{|c|}{ Control } & & \multicolumn{2}{|c|}{ Study } & \multicolumn{2}{|c|}{ Control } & & \multicolumn{2}{|c|}{ Study } & \multicolumn{2}{|c|}{ Control } & \\
\hline & No. & $\%$ & No. & $\%$ & & No. & $\%$ & No. & $\%$ & & No. & $\%$ & No. & $\%$ & \\
\hline $\begin{array}{l}\text { Muscles } \\
\text { atrophy }\end{array}$ & 0 & 0.0 & 4 & 13.3 & 0.121 & 0 & 0.0 & 14 & 46.7 & $<0.001 * *$ & 0 & 0.0 & 16 & 53.3 & $0.001 * *$ \\
\hline Joint pain & 3 & 10.0 & 7 & 23.3 & 0.299 & 4 & 13.3 & 24 & 80.0 & $<0.001 * *$ & 1 & 3.3 & 24 & 80.0 & $0.001 * *$ \\
\hline $\begin{array}{l}\text { Muscle } \\
\text { spasticity } \\
\text { (tone) }\end{array}$ & 0 & 0.0 & 2 & 6.7 & 0.472 & 6 & 20.0 & 22 & 73.3 & $<0.001 * *$ & 2 & 6.7 & 18 & 60.0 & $0.001 * *$ \\
\hline $\begin{array}{l}\text { Muscle } \\
\text { flaccid }\end{array}$ & 5 & 16.7 & 8 & 26.7 & 0.531 & 0 & 0.0 & 4 & 13.3 & 0.121 & 0 & 0.0 & 0 & 0.0 & ns \\
\hline $\begin{array}{l}\text { Limited } \\
\text { ROM }\end{array}$ & 4 & 13.3 & 8 & 76.7 & 0.333 & 2 & 6.7 & 25 & 83.3 & $<0.001 * *$ & 1 & 3.3 & 20 & 66.7 & $0.001 * *$ \\
\hline Stiff joints & 3 & 16.7 & 10 & 33.3 & 0.233 & 5 & 16.7 & 30 & 100.0 & $<0.001 * *$ & 2 & 6.7 & 25 & 83.3 & $0.001 * *$ \\
\hline $\begin{array}{l}\text { hemiplegic } \\
\text { shoulder } \\
\text { pain }\end{array}$ & 4 & 13.3 & 6 & 20.0 & 0.729 & 2 & 6.7 & 18 & 60.0 & $<0.001 * *$ & 2 & 6.7 & 29 & 96.7 & $0.001 * *$ \\
\hline $\begin{array}{l}\text { Shoulder } \\
\text { subluxation }\end{array}$ & 0 & 0.0 & 2 & 6.7 & 0.472 & 0 & 0.0 & 2 & 6.7 & 0.472 & 0 & 0.0 & 2 & 6.7 & 0.472 \\
\hline $\begin{array}{l}\text { Knee } \\
\text { flexion }\end{array}$ & 0 & 0.0 & 4 & 13.3 & 0.121 & 0 & 0.0 & 17 & 56.7 & $<0.001 * *$ & 0 & 0.0 & 17 & 56.7 & $0.001 * *$ \\
\hline
\end{tabular}




\begin{tabular}{|c|c|c|c|c|c|c|c|c|c|c|c|c|c|c|c|}
\hline \multirow{3}{*}{ variables } & \multicolumn{4}{|c|}{ Pre-implementing } & \multirow{3}{*}{ P. value } & \multicolumn{4}{|c|}{ Before discharge } & \multirow{3}{*}{ P. value } & \multicolumn{4}{|c|}{ After 2 months } & \multirow{3}{*}{ P. value } \\
\hline & \multicolumn{2}{|c|}{ Study } & \multicolumn{2}{|c|}{ Control } & & \multicolumn{2}{|c|}{ Study } & \multicolumn{2}{|c|}{ Control } & & \multicolumn{2}{|c|}{ Study } & \multicolumn{2}{|c|}{ Control } & \\
\hline & No. & $\%$ & No. & $\%$ & & No. & $\%$ & No. & $\%$ & & No. & $\%$ & No. & $\%$ & \\
\hline contracture & & & & & & & & & & & & & & & \\
\hline Foot drop & 0 & 0.0 & 4 & 13.3 & 0.121 & 0 & 0.0 & 12 & 40.0 & $<0.001 * *$ & 0 & 0.0 & 12 & 40.0 & $0.001 * *$ \\
\hline Toe curling & 0 & 0.0 & 4 & 13.3 & 0.121 & 0 & 0.0 & 9 & 30.0 & $0.004 * *$ & 0 & 0.0 & 9 & 30.0 & $0.004 * *$ \\
\hline $\begin{array}{l}\text { Finger } \\
\text { curling }\end{array}$ & 0 & 0.0 & 4 & 13.3 & 0.121 & 0 & 0.0 & 8 & 26.7 & $0.008 * *$ & 0 & 0.0 & 8 & 26.7 & $0.008 * *$ \\
\hline
\end{tabular}

Table (4): The total mean score of the study and control groups regarding their knowledge preimplementing before discharge, and after 2-month post implementing the exercise programme.

\begin{tabular}{|l|c|c|c|c|c|c|c|}
\hline \multicolumn{2}{|c|}{ variables } & $\begin{array}{c}\text { Pre- } \\
\text { implementing }\end{array}$ & $\begin{array}{c}\text { Before } \\
\text { discharge }\end{array}$ & $\begin{array}{c}\text { After 2 } \\
\text { months }\end{array}$ & P1 & P2 & P3 \\
\hline Study & Knowledge & $1.9 \pm 2.1$ & $14 \pm 1.4$ & $12.1 \pm 3.8$ & $<0.000^{* *}$ & $<0.000^{* *}$ & $0.168 \mathrm{~ns}$ \\
\hline Control & Knowledge & $1.8 \pm 2$ & $2.3 \pm 1.9$ & $7.2 \pm 4.4$ & $<0.000 * *$ & $<0.000^{*} *$ & $0.518 \mathrm{~ns}$ \\
\hline
\end{tabular}

Table (5): The total mean score of the study and control groups regarding their practice pre- implementing before discharge, and after 2-month post implementing the exercise programme.

\begin{tabular}{|l|l|c|c|c|c|c|c|}
\hline \multicolumn{2}{|c|}{ Variables } & $\begin{array}{c}\text { Pre- } \\
\text { implementing }\end{array}$ & $\begin{array}{c}\text { Before } \\
\text { discharge }\end{array}$ & $\begin{array}{c}\text { After 2 } \\
\text { months }\end{array}$ & P1 & P2 & P3 \\
\hline Study & Practice & $2.3 \pm 1.8$ & $8.9+0.9$ & $7.5+2.4$ & $<0.000^{* *}$ & $0.005^{* *}$ & $0.054 \mathrm{~ns}$ \\
\hline Control & Practice & $1.8 \pm 1.1$ & $2.5+1.7$ & $6+3.2$ & $<0.000^{* *}$ & $<0.000^{* *}$ & $<0.000^{* *}$ \\
\hline
\end{tabular}

P1: Comparison between pre-implementing and before discharge using paired t-test

P2: Comparison between pre-implementing and after 2 months using paired t-test

P3: Comparison between before discharge and after 2 months using paired t-test

Table (6) : Percentage distribution of the degree of spasticity according to Ashworth scale through pre, the post $I$, post II in both groups $($ no $=60)$.

\begin{tabular}{|c|c|c|c|c|c|c|c|c|c|c|c|c|c|c|c|}
\hline \multirow{3}{*}{ degree } & \multicolumn{4}{|c|}{ Pre-implementing } & \multirow{3}{*}{ P. value } & \multicolumn{4}{|c|}{ Before discharge } & \multirow{3}{*}{$\begin{array}{c}P . \\
\text { value }\end{array}$} & \multicolumn{4}{|c|}{ After 2 months } & \multirow{3}{*}{$\begin{array}{c}P . \\
\text { value }\end{array}$} \\
\hline & \multicolumn{2}{|c|}{ Study } & \multicolumn{2}{|c|}{ Control } & & \multicolumn{2}{|c|}{ Study } & \multicolumn{2}{|c|}{ Control } & & \multicolumn{2}{|c|}{ Study } & \multicolumn{2}{|c|}{ Control } & \\
\hline & No & $\%$ & No & $\%$ & & No & $\%$ & No & $\%$ & & No & $\%$ & No & $\%$ & \\
\hline 0 & 11 & 36.7 & 13 & $43 . .3$ & \multirow{6}{*}{$0.751^{\mathrm{ns}}$} & 0 & 0.0 & 1 & 3.3 & \multirow{6}{*}{$0.001 * *$} & 0 & 0.0 & 1 & 3.3 & \multirow{6}{*}{$\begin{array}{c}<0.001 * \\
*\end{array}$} \\
\hline 1 & 11 & 36.7 & 12 & 40.0 & & 1 & 3.3 & 7 & 23.3 & & 0 & 0.0 & 7 & 23.3 & \\
\hline 2 & 6 & 20.0 & 3 & 10.0 & & 6 & 20.0 & 14 & 46.7 & & 0 & 0.0 & 14 & 46.7 & \\
\hline 3 & 2 & 6.7 & 2 & 6.7 & & 16 & 53.3 & 8 & 26.7 & & 2 & 6.7 & 8 & 26.7 & \\
\hline 4 & 0 & 0.0 & 0 & 0.0 & & 7 & 23.3 & 0 & 0.0 & & 13 & 43.3 & 0 & 0.0 & \\
\hline 5 & 0 & 0.0 & 0 & 0.0 & & 0 & 0.0 & 0 & 0.0 & & 15 & 50.0 & 0 & 0.0 & \\
\hline
\end{tabular}

0 No movement or muscle contraction

2 Active movements with gravity eliminated.

4 Active movements with some resistance.
1 Trace contraction.

3 Active movements against gravity.

5 Active movements with full resistance.

Table( 7): The total score as regarding Scandinavian stroke scale in the studied groups pre, post I, post-II

\begin{tabular}{|c|c|c|c|c|c|c|c|c|c|c|c|c|c|c|c|}
\hline \multirow{3}{*}{$\begin{array}{c}\text { Maximal } \\
\text { score }\end{array}$} & \multicolumn{4}{|c|}{ Pre-implementing } & \multirow{3}{*}{ P. value } & \multicolumn{4}{|c|}{ Before discharge } & \multirow{3}{*}{ P. value } & \multicolumn{4}{|c|}{ After 2 months } & \multirow{3}{*}{ P. value } \\
\hline & \multicolumn{2}{|c|}{ Study } & \multicolumn{2}{|c|}{ Control } & & \multicolumn{2}{|c|}{ Study } & \multicolumn{2}{|c|}{ Control } & & \multicolumn{2}{|c|}{ Study } & \multicolumn{2}{|c|}{ Control } & \\
\hline & No. & $\%$ & No. & $\%$ & & No. & $\%$ & No. & $\%$ & & No. & $\%$ & No. & $\%$ & \\
\hline Low & 4 & 13.3 & 8 & 26.7 & \multirow{3}{*}{$0.399 \mathrm{~ns}$} & 0 & 0.0 & 5 & 16.7 & \multirow{3}{*}{$0.001 * *$} & 1 & 3.3 & 4 & 13.3 & \multirow{3}{*}{$0.001 * *$} \\
\hline Moderate & 20 & 66.7 & 18 & 60.0 & & 6 & 20.0 & 20 & 66.7 & & 0 & 0.0 & 20 & 66.7 & \\
\hline High & 6 & 20.0 & 4 & 13.3 & & 24 & 80.0 & 5 & 16.7 & & 29 & 96.7 & 6 & 20.0 & \\
\hline
\end{tabular}


Table (1): This table shows that socio-demographic characteristic of the studied group (control and study groups) as regarding age the majority of both groups aged $>46$ years old. Also, there was a predominance of males in both the study and the control groups (53.3\% and 56.7\%), as regard level of education; the educational levels in both groups were illiterate $(60 \%$ and 50\%). Looking at the occupation in both the study and control groups the highest percentage was a housewife (50\% and 46.7\%).The majority of both groups were having cerebral infarction $(76.7 \%)$. As regarding fahmey and Al-sherbeeny scale the highest percentage of patients' socioeconomic characteristic in both the study and control groups were having a low socioeconomic level $(83.4 \% \& 80 \%)$ with no statistically significant difference was found between the study and control groups regarding socioeconomic characteristic $\left(\mathrm{P}=0.288^{\mathrm{ns}}\right)$.

Table (2): This table demonstrates that more than half of control group suffered from one stroke recurrence (83.3\%) compared to $(66.7 \%)$ in the study group. As regard to the causes of stroke, the highest percentage of study group suffered from hypertension $(81.7 \%)$. The left side was the most affected paralytic side which occur with the highest percentage for both groups $(58.3 \%)$. while the majority of study group suffered from High blood pressure (80\%).

Table (3): This table demonstrates that, the patients' in control group more than study ones as regard the musculoskeletal complications; as regard muscles atrophy occurred in the control group $(\mathrm{P}=$ $0.001 * *, 0.001 * *)$, aches or pains in the muscles $(\mathrm{P}=$ $\left.0.001^{* *}, 0.001^{* *}\right)$, muscle spasticity $(\mathrm{P}=0.001 * *, 0.001 * *), \quad$ Limited $\operatorname{ROM}(\mathrm{P}$ $\left.=0.001^{* *}, 0.001 * *\right), \quad$ Stiff joints $\left(\mathrm{P}=0.001^{* *}, 0.001^{* *}\right), \quad$ Painful hemiplegic shoulder $(\mathrm{P}=0.001 * *, 0.001 * *)$,Knee flexion, foot drop, toe and finger curling contracture $\left(\mathrm{P}=0.001 * *, 0.001^{* *}\right)$ in the two phases before discharge and after 2 months.

Table (4): This table demonstrates that there is an increase in total mean score of patients' knowledge among study group after application of exercise $(14+$ 1.4) compared to $(2.3+1.9)$ in the control group.

Table (5): This table demonstrates that there is an increase in total mean score of patients' practice among study group after application of exercise $(8.9 \pm$ $0.9)$ compared to $(2.5 \pm 1.7)$ in the control group.

Table (6): This table it is clear that there is a decrease in patients' degree of spasticity according to Ashworth scale after application of exercise programme less than in pre-implementing in the study group than the control group and some patient suffered from flaccidity immediately after stroke and convert to increase the intensity of muscle tone.
Table (7): This table shows the highest percentage of patients' total score as regarding Scandinavian stroke scale in moderate and high level in the study than control groups were having a low score with a statistically significant difference was found between the study and control groups regarding Scandinavian stroke scale $(\mathrm{P}=0.001 * *, 0.001 * *)$.

\section{Discussion}

The current study revealed that, more than half of both groups were males the majority of patients in both groups aged between $57-67$ years, the highest percentages in both groups (study and control) were illiterate, housewife, 14 patients had cerebral haemorrhage and 46 patient had a cerebral infarction.

According to fahmy and el-sherbeeny scale the highest percentages of patients' socioeconomic characteristic in the present study were having low socioeconomic level Sposato \& Saposnik,(2011) assessed the relationship between socioeconomic status and stroke in 23 studies. The researchers found that populations with lower socioeconomic status had a higher incidence of stroke and an earlier age of stroke onset ( $\mathrm{p}<0.001$ for all).

In the present study, the stroke had occurred for the first time in 45 patients and was recurrent 15 patients. The result of the present study according to health history revealed that more than half of the both group were having hypertension and 24 patients were having diabetes mellitus and 15 patients complain from chronic disease.

The incidence of musculoskeletal complications in control sample was higher than the study group and having unsatisfactory knowledge regarding stroke.

The results of the present study revealed that there was a significant statistical difference between the control and study groups regarding their knowledge and practice pre- implementing, before discharge and after 2-month post implementing the exercise programme.

The current study revealed that, decrease in patients' degree of spasticity according to Ashworth scale after application of exercise less than in pretest ,before discharge and after 2 months in study group than control group Yocheved \& michal, (2011) reported that, Paretic muscle strength improved after training $(p<0.05)$ while tone remained consistent $(p>0.87)$.

The results of the present study revealed that there was a significant statistical difference between the control and study groups regarding Scandinavian stroke scale pre- implementing, before discharge and after 2-month post implementing the exercise programme. 


\section{Conclusions}

providing a successful physical exercise programme for stroke patients was much more effective on the outcome of patients than those patients in the control group who received routine hospital care. Also, the mean score level of knowledge of the study group patients in the time of follow-up was higher than the mean score level of knowledge of control group patients who didn't receive the exercise programme.

\section{Recommendations}

- Nurses should develop exercise/physical activity programs to help improve the outcome of their stroke patients.

- The researcher recommended with the exercise programme should begin early after stroke.

- A successful physical exercise programme should be definitively identified for each stroke patients.

\section{Reference}

1. Ayman Y., Essa T., Helmy \& Sameh S., (2011): American Science Journal, Study of Incidence, Risk Factors and Outcome of Acute Cerebrovascular Stroke Patients Admitted to Alexandria Main University Hospital 7(11); PP.316:329.

2. Banks G., Bernhardt J., Churilov L., Cumming T., (2012): Exercise preferences are different after stroke. Stroke Res Treat:890946.

3. Carison K., (2009): AACN Advanced Critical Care Nursing, American Association Critical Care Nurses Saunders $1^{\text {st }}$ ed., pp576:316.

4. Jiricka, M., (2008): Activity tolerance and fatigue pathophysiology: concepts of altered health states. In: Porth, C.M. (ed) Essentials of Pathophysiology: Concepts of Altered Health States. Philadelphia, PA: Lippincott Williams \& Wilkins.

http://www.nursingtimes.net/effects-of-bedrest-3musculoskeletal-and-immune-systems-skin-andself-perception/5003298.article

5. Lina B., Asa L., Christian B., \& Michael N., (2012): BMC Neurology journals, The Effects of a Rhythm and Music-Based Therapy Program and Therapeutic Riding in Late Recovery Phase following Stroke: a Study Protocol for a Threearmed Randomized Controlled Trial 12(141); pp. 1471: 2377.

6. Lindenstrom., (1991): Scandinavian stroke scaleProvided by the Internet Stroke Center www.strokecenter.org.

7. Masoud M., Astewart T., Kathryn A., Andrew, Richard T., \& Stephen R., (2012): Neurosurgery Psychiatry, Cerebrovascular
Disease in 48 Countries: Secular Trends in Mortality 1950-2005 PP. 83:138.

8. Muller E., (1970); Influence of training and of inactivity on muscle strength. Arch Phys Med Rehabil. 1970;51(8)Pp:449-462.

9. National stroke association, (2010).

10. Sposato L., Saposnik G., (2011): Gross domestic product and health expenditure associated with incidence, 30-day fatality, and age at stroke onset. Stroke, DOI: 10.1161/strokeaha.111.632158. Available here.http://www.medscape.com/viewarticle/7527 49.

11. Yocheved L., \& Michal E., (2011): Neuro rehabilitation Journal, Does Sensory Transcutaneous Electrical Stimulation Enhance Motor Recovery Following a Stroke? A Systematic Review 9(25); pp. 799:809 